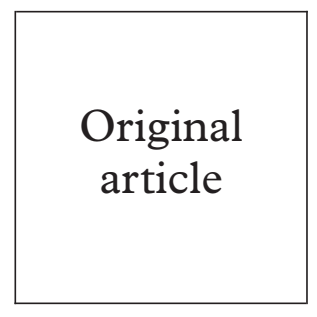

Department of Epidemiology and Public Health, Imperial College of Science, Technology and Medicine at $\mathbf{S t}$ Mary's, Norfolk Place, London W2 1PG, UK A Ziersch

Working Men Project, St Mary's Hospital, Praed Street London W2 1NY, UK

J Gaffney

D R Tomlinson

Correspondence to: Anna Ziersch, Department of Public Health, Flinders University of South Australia, PO Box 2100, Adelaide 5001, Australia anna.ziersch@flinders.edu.au

Accepted for publication 7 June 2000

\title{
STI prevention and the male sex industry in London: evaluating a pilot peer education programme
}

\author{
A Ziersch, J Gaffney, D R Tomlinson
}

Objective: To evaluate the effectiveness of a pilot peer education STI prevention programme with male sex workers.

Design: A process and outcome evaluation of the pilot programme undertaken in three London male escort agencies, using a quasi-experimental design.

Subjects: Workers in three London escort agencies, including 88 who completed a questionnaire, five peer educators, and a further 16 men (including management) working in two of these agencies. Methods: A peer education STI prevention programme run by the Working Men Project (WMP), a specialist sexual health service for male sex workers, was piloted in two London escort agencies. Five male sex workers participated in a 2 day peer education training programme. They then returned to their respective agencies to disseminate information and condoms, in an attempt to influence norms of behaviour.

An outcome evaluation aimed to assess changes in STI related knowledge, high risk sexual behaviour, and attendance at a sexual health service. A pre-intervention questionnaire assessing variables such as STI related knowledge, sexual behaviour, and demographic information was administered in both agency A and agency B and a third agency, C, which acted as a control. Ten weeks after the peer educators returned to their agencies, the same questionnaire was administered in the same agencies. Peer educator referrals to the WMP were also recorded over this time period. The process evaluation involved interviews and focus groups with peer educators, and the completion of diaries about their experiences in the role. A further 16 men working in the agencies (including managers and an owner) were interviewed about their experience of the programme. Participant observation was also undertaken through regular outreach work to the agencies.

Results: 57 men completed the questionnaire at time 1 and 44 at time 2 . Unfortunately, only 13 of these were matched, precluding any meaningful analysis of change in STI related knowledge and sexual behaviour. The questionnaire provided a profile of the men working in the agencies. Of the 88 men who completed the questionnaire at least once, the majority were homosexual, and in their late teens/early 20s. Most were of a "white" ethnic group, though there was some range within these categories. Most preferred to speak English and education levels were high. Relative STI knowledge revealed a high understanding of HIV and hepatitis B, moderate understanding of gonorrhoea, syphilis, genital warts and herpes, and little knowledge of non-specific urethritis (NSU) or chlamydia. Sexual behaviour suggested a highly sexually active population with both male and female paying and non-paying partners. Condom use was highest for paying partners, particularly for anal sex. Condom use for oral sex with all partners was less consistent, and condom use for all types of sex with regular partners was lower than with other partners. The small number of men engaging in vaginal sex with paying and regular partners were less likely to use condoms. 26 new patients registered at the WMP as a result of peer educator referrals, representing $65 \%$ of all new contacts over the study period. The process evaluation revealed that while the training programme was considered adequate and while peer educators felt the programme and their roles to be a success, their experience of the role was difficult. The role of management support was crucial in supporting the programme. The assumption that "peers" are particularly effective educators was not borne out by the results. While peers were considered suitable to discuss some aspects of the industry, many preferred to consult "professionals" about health related matters. The concept of "peers" was problematic with most of the men drawing "peers" from subgroups within the agencies. Other constraints on behaviour such as a lack of power, particularly with regard to a lack of management support, or poverty, had a substantial impact on behaviour which were not influenced by the peer educators.

Conclusions: The study illustrated the difficulties of utilising quasi-experimental evaluation methodology with this client group. It also demonstrated the limitations of peer education based on information provision health education models which focus on individual behaviour change. Suggestions are given for future interventions. (Sex Transm Inf 2000;76:447-453)

Keywords: male sex workers; peer education; evaluation

\section{Introduction}

In the United Kingdom, there have been 47807 reported cases of HIV infection, of which $29366(61 \%)$ are thought to have been homosexually transmitted. ${ }^{1}$ There are no routine data on the prevalence of HIV among male sex workers in the United Kingdom, though one study in London found that $11 \%$ of male sex workers tested at a specialist sexual health service were HIV positive. ${ }^{2}$ High levels of other STIs have also been found among this population, which may also be important in facilitating HIV transmission. ${ }^{3}$ However, the illegal and stigmatised nature of prostitution means that many 
male sex workers are reluctant to attend generic sexual health services, or if they do, fail to reveal to staff their involvement in selling sex. ${ }^{4}$

While sex workers do not constitute a "risk group" per se, ${ }^{5}$ male sex workers are often associated with a cluster of risk behaviours such as injecting drug use, ${ }^{6}$ high rates of anal sex, ${ }^{37}$ and inconsistent condom use (though reported rates vary ${ }^{3}$ ), and hence may be important in STI transmission. In addition, unsafe sex with nonpaying partners is widespread, which may provide a significant route for STI infection. ${ }^{8}{ }^{9}$

Peer education has become a popular approach for health interventions with both male and female sex workers. Research has found that peer group and social norms are important determinants of behaviour for a number of groups (see Fennell ${ }^{10}$ and Rhodes ${ }^{11}$ for reviews). Similarly, research has also suggested that social consensus and peer endorsement of sexual behaviour are among the most important determinants of behaviour change. ${ }^{112}$ For this reason, peer education programmes have begun to utilise the skills of "indigenous" peer educators. That is, individuals from "target populations" who are seen to be key or central in social networks, have been employed as health educators. ${ }^{11}$ The World Health Organization (WHO) guidelines for policy on STI control in prostitution recommends the involvement of sex workers and their partners in STI prevention initiatives, suggesting that current or ex-sex workers be employed as educators and coordinators. ${ }^{13}$

Peers and Johnston ${ }^{14}$ argue that peer education is particularly difficult to evaluate because of its loosely defined aims and emergent activities, and a number of reviews of peer education initiatives have revealed few systematic evaluations. ${ }^{10}{ }^{15}$ Milburn, ${ }^{15}$ in her review of peer education initiatives with young people, found many initiatives had poorly specified theoretical components and warned of the difficulties of "artificially reconstructing social processes". Campbell, ${ }^{16}$ writing about peer education and safer sexual behaviour in young people, has pointed to the limitations of peer education in addressing constraints on behavioural change, particularly at the community and macrosocial level. However, Rhodes ${ }^{11}$ argues that existing evaluations of peer education suggest that it is a more effective method of behaviour change than individually based interventions.

\section{Methods}

The Working Men Project (WMP), based at St Mary's Hospital, London, provides a specialist sexual health service for men who sell sex to men. This project initiated a pilot peer education initiative with men working in off-street prostitution in escort agencies where sex takes place on the premises, to attempt new ways to access harder to reach workers. The initiative wished to utilise the influential role of the peers to impart information and "model" appropriate behaviour and aimed to:

- Increase sexual health knowledge, as STI knowledge has been shown to be an important precondition for safer sexual behaviour in prostitution ${ }^{17}$
- Reduce high risk sexual behaviour - that is, encourage the use of condoms for anal, vaginal, and oral sex

- Improve sexual health through the encouragement of regular screening at the Working Men Project.

\section{THE INTERVENTION}

The WMP was currently undertaking visits to a number of agencies, distributing condoms, discussing STIs and safer sex, and making appointments at the WMP. Eight men from two agencies ( $A$ and $B$ ) were invited to participate in a 2 day training programme. Workers from a third agency, C, did not participate, and this agency acted as a control. Agencies A and $\mathrm{B}$ were chosen to receive the intervention as they were the largest agencies and the WMP was somewhat familiar with the networks within them. Agency $\mathrm{C}$ was the smaller of the agencies and its social networks were less well known. The participants in the training programme were selected on the grounds that they were known by the WMP to be key people in the agency networks, already informally referring patients to the project, and were committed to STI prevention. Five men attended the programme. The first day examined aspects of HIV, information on sexually transmitted infections, and the benefits of regular sexual health screening. The second day explored personal growth and communication and negotiation skills. Peer educators (PEs) participated in practical role playing exercises.

After the completion of the training programme, the PEs went back into their respective agencies (two to agency $\mathrm{A}$ and three to agency B) with a range of health education materials, to distribute condoms, and disseminate what they had learned. Unfortunately, two of the PEs (one from each agency) left the programme, with one working privately and the other leaving prostitution altogether. WMP visits continued to all agencies.

EVALUATION METHODOLOGY

The study was conducted over a 10 week period from October to December 1995. Both a process and outcome evaluation were conducted to assess the effectiveness of the programme in reaching its aims.

\section{Outcome evaluation}

Experimental methodology with randomised allocation was not feasible owing to the established nature of agency employees. However, quasi-experimental methodology was utilised with pre-intervention and postintervention measures and non-random experimental and control groups. The two experimental groups received the peer education intervention, in addition to existing health promotion activities. The control group received only existing health promotion.

A questionnaire was developed to assess a range of aspects including STI awareness and knowledge of transmission, prevention, and treatment; sexual behaviour; and demographic information. The questionnaire was assessed 
by a panel of appropriate experts for construct and content validity, and piloted three times with members of the subject group, and altered accordingly.

The questionnaires, including an information sheet outlining ethical considerations, were distributed to men working in the agencies on existing scheduled visits. Questionnaires were completed in the presence of the researchers and, once completed, were returned in sealed envelopes. Questionnaires were anonymous, though participants were asked to give an "identifier" of the month, year, and town of their birth for future comparison of responses. At the end of the 10 week study period, the questionnaires were again distributed to the men working in all three agencies. The pre-intervention and post-intervention sexual health knowledge scores and condom use for the relevant sexual behaviours were compared in $\mathrm{A}$ and $\mathrm{B}$, with agency $\mathrm{C}$ acting as a control.

In addition, the WMP recorded the number of new patients claiming to have registered as a result of interaction with a $\mathrm{PE}$.

\section{Process evaluation}

At the end of the second day of the training programme a focus group was held with the PEs to evaluate the training.

Peer educators were asked to complete daily diaries over the intervention period detailing the number and nature of contacts they had had with fellow workers. They were also asked to complete weekly diaries, where they recorded their experiences of the programme over the previous week.

Individual interviews were also undertaken with the PEs. In addition, two group meetings over the intervention period provided practical support as well as an opportunity to evaluate the programme. Finally, a focus group with the PEs was run at the end of the programme to reflect on overall experiences of the programme, its successes and failures, and suggestions for future initiatives.

Interviews were also undertaken with the owner and manager of agency $\mathrm{A}$ and the manager of agency B, in addition to 13 men working in the two participating agencies recruited through the initial questionnaire.

Monthly visits to the agencies by the WMP, attendance at a party at agency $\mathrm{A}$, and informal discussion enabled ethnographic research and participant observation, particularly of those who declined to be interviewed, and attempted to address the potential biases of respondents' self reports. ${ }^{18}$

The study received ethical approval through the WMP at St Mary's Hospital, London.

\section{Results}

OUTCOME MEASURES

Exact figures of men working at the agencies at each time were not known, though the majority of workers were observed to have completed the questionnaire. However, owing to the rapid turnover of men working in the three agencies, the proportion of the sample who were still available at the second administration of the
Table 1 Number of men completing the questionnaire at time 1 and time 2

\begin{tabular}{llll}
\hline Agency & Time 1 & Time 2 & Time 1 and 2 \\
\hline Agency A & 26 & 19 & 4 \\
Agency B & 22 & 18 & 5 \\
Agency C & 11 & 7 & 6 \\
\hline
\end{tabular}

questionnaire was very small, as can be seen from table 1. Additionally, over the study period, a number of men had changed agencies, confounding the group allocations. These factors preclude any meaningful comparison of the questionnaire data for evaluation purposes. ${ }^{1}$

However, the questionnaire data provide some insight into the profile of men working in these agencies. Eighty eight men completed the questionnaire at least once. The mean age of respondents was 24 years. Two of the men were 17 , under the age of consent for homosexual sex. Sixty six $(75 \%)$ were identified as homosexual, $11(13 \%)$ as bisexual, two $(2 \%)$ as heterosexual, and four (5\%) as other (five (6\%) missing) (percentages do not add up to 100 because of rounding). Thirty two (37\%) were identified as "white English/Scottish/Welsh", seven (8\%) as "white Irish", and $29(33 \%)$ as "white other" (largely other European communities and South Americans). Three (3\%) were identified as "black African", three (3\%) as "black-Caribbean," and three (3\%) as "black other". There was one Indian and one Chinese respondent and four (5\%) men from "other" ethnic groups (five (6\%) missing).

The majority of respondents, 58 (66\%), preferred to speak English, with Spanish, Portuguese, French, and Italian being other favoured languages. Seventy six (86\%) men had completed a secondary school education or equivalent. Of these, $49(64 \%)$ had further qualifications, with 19 (39\%) of these to degree level.

As can be seen from table 2, STI knowledge varied significantly depending on the infection. There was particularly high knowledge of HIV, which could be expected given the reported exposure to HIV prevention campaigns. Hepatitis B was also high, possibly because of a targeted education campaign during the study resulting from a hepatitis B scare in the agencies. There was moderate knowledge of genital warts, herpes, syphilis, and gonorrhoea, but little understanding of chlamydia and NSU.

The median number of paying partners over the previous 7 days was six (range 0-25). Forty nine $(58 \%)$ had had sex with a casual male partner in the past 3 months and five (7\%) with a casual female partner. Forty nine $(57 \%)$ of

Table 2 Median percentage score of STD knowledge

\begin{tabular}{ll}
\hline STI & Percentage score \\
\hline HIV & 83 \\
Hepatitis B & 89 \\
Genital warts & 52 \\
Herpes & 59 \\
Chlamydia & 0 \\
NSU & 0 \\
Syphilis & 58 \\
Gonorrhoea & 62 \\
\hline
\end{tabular}


Table 3 Sexual behaviour and condom use with paying partners in past 7 days

\begin{tabular}{|c|c|c|c|c|}
\hline \multirow[b]{2}{*}{$\begin{array}{l}\text { Type of sexual } \\
\text { behaviour }\end{array}$} & \multicolumn{2}{|c|}{ Sexual behaviour } & \multicolumn{2}{|l|}{ Related condom use } \\
\hline & $\begin{array}{l}\text { No (\%) } \\
\text { engaging }\end{array}$ & $\begin{array}{l}\text { No (\%) } \\
\text { missing }\end{array}$ & $\begin{array}{l}\text { No (\%) of these not } \\
\text { "always" }{ }^{\circ} \text { using a condom }\end{array}$ & $\begin{array}{l}\text { No (\%) } \\
\text { missing }\end{array}$ \\
\hline Passive anal sex & $36(41)$ & $14(16)$ & $3(8)$ & $3(8)$ \\
\hline Active anal sex & $55(63)$ & $11(13)$ & $4(7)$ & $0(0)$ \\
\hline Passive oral sex & $74(84)$ & $7(8)$ & $47(64)$ & $4(5)$ \\
\hline Active oral sex & $71(81)$ & $9(10)$ & $36(51)$ & $2(3)$ \\
\hline Vaginal sex & $8(9)$ & $14(16)$ & $4(50)$ & $0(0)$ \\
\hline Sex toys & $7(8)$ & $10(11)$ & $1(14)$ & $5(7)$ \\
\hline
\end{tabular}

*The three categories of condom use "never," "sometimes," and "always" were collapsed to "always" and "not always."

the men had had sex with a regular male partner in the past 3 months and six $(7 \%)$ with a regular female partner.

As can be seen from table 3, oral sex, both passive and active, was the most common sexual behaviour with paying partners, with over half not consistently using condoms. Anal sex, particularly active, was also reasonably common though condom use was much higher. A small number had engaged in vaginal sex, though only half of these always used condoms. Similarly, a small number had used sex toys but condom use was high.

Tables 4 and 5 show that most men with casual partners had had oral sex, both passive and active, with low rates of condom use. Anal sex was also reasonably common, with slightly higher numbers than for paying partners not using condoms always. A small number had had vaginal sex with casual partners, of whom all used condoms always. A similar number had used sex toys, though two had not always used condoms. Sexual behaviour with regular partners was similar to that with casual, though anal sex was more common with lower condom use. The small number of men engaging in vaginal sex with a regular partner, was not consistent with condom use, nor were those using sex toys.

Table 4 Sexual behaviour and condom use with casual partners in past 3 months

\begin{tabular}{|c|c|c|c|c|}
\hline \multirow[b]{2}{*}{$\begin{array}{l}\text { Type of sexual } \\
\text { behaviour }\end{array}$} & \multicolumn{2}{|c|}{ Sexual behaviour } & \multicolumn{2}{|l|}{ Related condom use } \\
\hline & $\begin{array}{l}\text { No (\%) } \\
\text { engaging }\end{array}$ & $\begin{array}{l}\text { No (\%) } \\
\text { missing }\end{array}$ & $\begin{array}{l}\text { No (\%) of these not } \\
\text { "always" } \text { using a condom }\end{array}$ & $\begin{array}{l}\text { No (\%) } \\
\text { missing }\end{array}$ \\
\hline Passive anal sex & $29(56)$ & $7(8)$ & $5(17)$ & $0(0)$ \\
\hline Active anal sex & $33(63)$ & $7(8)$ & $5(15)$ & $0(0)$ \\
\hline Passive oral sex & $49(94)$ & $5(6)$ & $36(74)$ & $7(14)$ \\
\hline Active oral sex & $42(81)$ & $7(8)$ & $31(74)$ & $3(10)$ \\
\hline Vaginal sex & $5(10)$ & $6(7)$ & $0(0)$ & $2(40)$ \\
\hline Sex toys & $5(10)$ & $9(10)$ & $2(40)$ & $2(40)$ \\
\hline
\end{tabular}

*The three categories of condom use "never," "sometimes," and "always" were collapsed to "always" and "not always."

Table 5 Sexual behaviour and condom use with regular partners in the past 3 months

\begin{tabular}{|c|c|c|c|c|}
\hline \multirow[b]{2}{*}{$\begin{array}{l}\text { Type of sexual } \\
\text { behaviour }\end{array}$} & \multicolumn{2}{|c|}{ Sexual behaviour } & \multicolumn{2}{|l|}{ Related condom use } \\
\hline & $\begin{array}{l}\text { No (\%) } \\
\text { engaging in } \\
\text { behaviour }\end{array}$ & $\begin{array}{l}\text { No (\%) } \\
\text { missing }\end{array}$ & $\begin{array}{l}\text { No (\%) of these not } \\
\text { "always" } \text { using a condom }\end{array}$ & $\begin{array}{l}\text { No (\%) } \\
\text { missing }\end{array}$ \\
\hline Passive anal sex & $45(83)$ & $5(6)$ & $14(31)$ & $3(7)$ \\
\hline Active anal sex & $49(91)$ & $4(5)$ & $10(33)$ & $5(10)$ \\
\hline Passive oral sex & $56(96)$ & $3(3)$ & $38(68)$ & $9(15)$ \\
\hline Active oral sex & $53(98)$ & $3(3) \dagger$ & $37(70)$ & $8(15)$ \\
\hline Vaginal sex & $8(15)$ & $6(7)$ & $3(38)$ & $2(25)$ \\
\hline Sex toys & $10(19)$ & $5(6)$ & $7(70)$ & $0(0)$ \\
\hline
\end{tabular}

*The three categories of condom use "never," "sometimes," and "always" were collapsed to "always" and "not always."

†Percentages add up to more than 100 because of rounding.
Sexual behaviour and condom use should be considered in the light of sometimes high rates of missing data (see tables 3-5).

Referrals to WMP revealed that PE activities had a significant impact on new patient recruitment at the WMP. During the study period, 26 new patients registering with the WMP were referred by a PE, representing $65 \%$ of the new patients attending during that time.

PROCESS MEASURES

\section{Peer educator experience}

The training programme was evaluated positively with all PEs feeling that they had adequate skills to take on their new role.

Interviews, focus groups, and the diaries suggested that the PEs found their involvement in the programme to be beneficial and felt that they had been successful in a number of ways, particularly in their referral success and also in improving their own knowledge and expertise. A number of suggestions of the PEs were followed up by the WMP - for example, hepatitis B information cards, a condom bag with sexual health information, and STI information cards with photographs (though these developments were not completed until after the study). However, at times the PEs felt unappreciated and unsupported in their agencies and those working in agency B were actively discriminated against (see below). By the end of the study all workers had left the agencies, symptomatic both of the transient nature of the work, but also of their difficulties in the role.

\section{Management experience}

The management of the two intervention agencies differed in their experience of the peer education programme. At agency $\mathrm{A}$, both the manager and owner of the agency were fully supportive of both the WMP and the peer education programme. They provided important support to the PE for working in the agency and encouraged new workers to meet with him. In contrast, at agency B the owner was hostile to the programme, fearful that encouraging the use of condoms would lose him business. When it became apparent that the two PEs were influencing workers' decision to use condoms for oral sex, he fired anybody associating with them and subsequently ensured that the PEs got little or no work. Attempts at intervention by the WMP failed.

\section{Experience of men working in the agencies}

Interviews with the men working in the agencies revealed that "peers" were a preferred and more effective source of advice and information, in only some circumstances, and for only part of the sample. A number of those interviewed said that they would turn to peers for advice and information, and felt that sometimes "peers" were better able to understand their circumstances than outside health professionals. For example, ideas for eroticising safer sex came most appropriately from those working in the profession. However, a large proportion of the men stressed health professionals as a more appropriate source of 
information/advice for most matters. It was felt that health professionals were just that, "professionals", with codes of ethics, rules of confidentiality, etc.

"To me, the person in the white suit, or going to the hospital, they're professional, otherwise they wouldn't be there. And to me, I mean everybody knows that is confidential, what happens between you and me, and in the hospital" (Peter)

(No details are given about the men interviewed as this would provide identifying information.)

A number of men expressed the potential for a conflict of interest with fellow workers and concerns of confidentiality in discussing health matters with a peer. Many spoke of the importance of talking to an "outsider".

"If you have got an embarrassing question, then, whatever way you look at it you want someone who is a bit more of an outsider." (Michael)

In contrast with the role of potential PEs, the role of health professionals was much clearer to them:

"They're [the peer educators] there for us, but they're not really. Like we know that you [WMP staff] are really there for us." (Peter) In addition to the importance of health professionals, most noted "gay" health education campaigns as their favoured source of information.

With regard to the role of social norms and peer influence, it appeared that both informal and formal norms existed in the agency relating to sexual behaviour and other elements of working practice. A formal house rule existed in agency $\mathrm{A}$ that condoms be used for anal sex with clients. Anyone found not to be doing so would be sacked. In addition, an informal norm existed among the men that this be adhered to. A similar informal rule existed in agency $B$, though this lacked management support. Despite the existence of a group norm in both agencies for condom use for anal sex, rumours existed that this norm was breached, supported by the questionnaire data, largely relating to financial inducements (discussed below).

The influence of PEs on these sexual norms was difficult to assess. Many subgroups existed within the agencies, based on elements such as lifestyle, nationality and language, which themselves had sets of norms (for example, relating to condom use, oral sex, kissing and, in some instances, anal sex). The social life of the agencies formed an important part of its operation. It was from these subgroups that people appeared to more directly identify "peers" and to these people whom they looked to for information and advice.

A number of other factors influenced the sexual behaviours of the men and provided barriers to the adherence of social norms. The role of power within the profession was identified as very important by the majority. Many spoke of the mind games and power struggles that often occurred between client and workers. Similarly, the manager of one of the agencies spoke of the need customers had to be in control of the sexual encounters, citing this as one of the reasons for difficulties about condom use. Clients sometimes complained about condom use or would refuse a man on the grounds that he wanted to use condoms. Management support was vital in these circumstances. In agency A, all of those interviewed felt they had management support to refuse a customer or a sexual act. Clients known to have removed condoms were barred from the agency. However, in agency B, if three complaints were made about a man, for whatever reason, he was sacked.

All of the men interviewed reported that they had been offered financial inducements for unsafe sex. It was reported that some of the men working in the agencies were suffering extreme financial hardship:

"It's very very hard in London. It's a very difficult city... . You don't have a security, a social security that gives you money every week, you have to work." (Dan)

This was particularly relevant for illegal immigrants. For example, it was reported that the manager of agency $\mathrm{B}$ employed under-age men and illegal immigrants, and made it clear to them that no other agency would do so. It was noted that many illegal immigrants thought they couldn't use health services or were reluctant to do so fearing that they would be traced through medical records. Laws in general also impacted on people's behaviour in terms of, for example, responding to management policy over health and safety issues in the agencies or client behaviour.

While most workers knew the STI risks associated with oral sex without a condom, in some cases an active decision was made not to use condoms after a "cost-benefit analysis" of the extra money they could earn.

\section{Discussion}

The failure of the quasi-experimental design illustrates the inherent difficulty of undertaking an evaluation using these methods with such a stigmatised group, where "most of the boys work/have a break/change agencies/work/back to the old agency, etc" (quoted from a peer educator).

The outcome evaluation was inconclusive with regard to the effectiveness of peer education in terms of increased sexual health knowledge and reduced risky sexual behaviour.

However, the questionnaire data provide a picture of the men working in these agencies, important if health education is to be appropriately targeted. The majority of the men were homosexual and in their late teens/early 20 s. Most were of a "white" ethnic group, though there was some range within these categories, and preferred to speak English. Education levels were high. Overall level of STI knowledge is difficult to ascertain, as there are no norms associated with the survey instrument. However, relative levels of knowledge found that HIV and hepatitis B were high, with some areas badly lacking.

The results suggest a highly sexually active population with both male and female paying and non-paying partners. Condom use was 
highest for paying partners, for anal sex, confirming the qualitative data on the norms for anal sex. Similarly, condom use for oral sex with all partners was less consistent as suggested by the interviews with the men about different norms for oral sex. Condom use with regular partners was less consistent, particularly around anal sex. These findings are consistent with de Graaf et al's findings among Dutch male sex workers that condom use for penetrative sexual activity decreased as familiarity with partner type increased. ${ }^{19}$ Those engaging in vaginal sex with paying and regular partners were also less likely to use condoms, suggesting a perception of lower risk, though these numbers were small.

Despite the failure of the measures to illustrate changes in STI knowledge and sexual behaviour and condom use, it did show a significant increase in referrals to the WMP, important given the reluctance of many sex workers to access sexual health services.

The training programme itself appeared adequate in terms of equipping the educators and the PEs themselves felt the programme and their role in it to be a success, again largely in relation to the referral process. However, PEs required a lot of support, particularly in the face of management opposition.

The assumption that "peers" are particularly effective educators, was not borne out by the results. Interviews with the sample suggested that the medical profession and the gay community in general, were more relevant to health education for these men than "sex worker peers". Similarly, the influence of PEs on relevant social norms, was a complex process. This process related to group membership, broader notions of social norms and peer affiliation.

Management interference and financial considerations provided significant obstacles to the impact of the programme. The extent of management power, was significantly influenced by material circumstances and also immigration status. The impact of these factors illustrates the limitations of peer education based on information provision health education models, which focus solely on individual behaviour change. ${ }^{1120}$ More collective forms of action, utilising "social transformatory" 20 models, which aim to enhance health by bringing about broader societal change, may be more appropriate for this group.

\section{Conclusion}

This evaluation of a pilot programme illustrates the difficulties of undertaking peer education with this client group. Future peer education initiatives may need to look at the various informational needs and sources of trusted information of specific subject groups, as this is likely to differ. It might be important to utilise the skills of many different "types" of sex workers in peer education, addressing social norms of various levels. This may involve, for example, tapping a more general homosexual norm or appealing to cultural affiliations.

Health interventions may need to develop strategies for facilitating a collective identity of consciousness. This will require a move towards models of community action, with ownership by the groups involved. Similarly, the role of power and material and structural factors in behavioural choices points to the need to take a broader approach, such as involving other participants in the sex industry such as the managers and clients, or addressing the implications of legislation on health and occupational safety.

The role of maintaining momentum in initiatives and the provision of adequate support for peer educators should be factored into intervention budgets. Peer education in this context is not the "cheap option".

Finally, the study stresses the importance of considering the context in which a peer education programme will operate and the specific group targeted. Even information such as said by one worker "we don't get up very early" is important in terms of, for example, organising training programmes or support meetings. Similarly, this study involved men working in London agencies where sex takes place on the premises, findings may differ for prostitution in other settings.

The authors would like to thank the peer educators and the other men who participated in this research. We would also like to thank Dr Catherine Campbell and Dr David Tomlinson for their assistance and advice over the course of this work, and anonymous referees for their comments on previous drafts of this article.

Contributors: AZ and JG designed and administered the questionnaire, and wrote the paper. AZ designed and administered the diaries, undertook the qualitative work, and compiled the statistics.

1 Public Health Laboratory Service AIDS Centre (HIV, STD Division, Communicable Disease Surveillance Centre) AIDS/HIV Quarterly Surveillance Tables-UK data to end of June 1998 .

2 The prevalence of sexually transmissible diseases in men who sell sex to men (commercial sex workers). Abstract for the 11th Meeting of the International Society for STD Research, 27-30 Aug 1995, New Orleans, Louisiana (USA).

3 McKeganey N. Prostitution and HIV: what do we know and where might research be targetted in the future? AIDS 1994;8:1215-26.

4 Gaffney J. An analysis of the role of the male sexual health nurse practitioner in HIV prevention with male sex workers. London, practitioner in HIV prevention with male sex workers. London, 1994.

5 Tomlinson D, Hillman R, Harris J, et al. Screening for sexually transmitted disease in London-based male prostitutes. Genitourin Med 1991;67:103-6.

6 Day S, Ziersch A, Casey M, et al. UK Country Report. In: Mak R, ed. European Project for AIDS Prevention in Prostitution. Gent: Academia Press, 1996.

7 Hickson F, Weatherburn P, Hows J, et al. Selling safer sex: male masseurs and escorts in the UK. In: Aggleton P, Davies P, Hart G, eds. AIDS: Foundations for the future. London: Taylor and Francis, 1994

8 Robinson T, Davies P. London's homosexual male prostitutes: power, peer groups and HIV. In: Aggleton P, Hart G, Davies P, eds. AIDS: responses, interventions and care. London: Falmer Press, 1991.

9 Morgan-Thomas R, Plant MA, Plant ML, et al. Risks of Morgan-Thomas R, Plant MA, Plant ML, et al. Risks of
AIDS among workers in the 'sex industry': Some initial AIDS among workers in the 'sex industry': Some init
results from a Scottish study. BMF 1989;299:148-9.

10 Fennell R. A review of evaluations of peer education Fennell R. A review of evaluations of pe
programmes. $f$ Am Coll Hlth 1993;41:251-3.

11 Rhodes T. Outreach, community change and community empowerment: Contradictions for public health and health promotion. In: Aggleton P, Davies P, Hart G, eds. AIDS: foundations for the future. London: Taylor and Francis, 1994:48-64

12 Kippax S, Crawford J. Flaws in the theory of reasoned action. In: Terry $\mathrm{D}$ et al, eds. The theory of reasoned action: its application for aids preventative behaviour. Oxford: Pergamon, 1993.

13 Campbell CA. Prostitution, AIDS and preventative health behaviour. Soc Sci Med 1991;32:1367-78.

14 Peers IS, Johnston M. Theory, utility and stakeholders: Methodological issues in evaluating a community project on HIV/AIDS. In: Boulton M, ed. Challenge and innovation: methodological advances in social research on hiv/aids. London: Taylor and Francis, 1994. 
15 Milburn K. A critical review of peer education with young people with special reference to sexual health. Health Educ people with special refer
Res 1995;10:407-20.

16 Campbell C. Peer education and safe sexual behaviour amongst adolescents. In: Moore $\mathrm{H}$, ed. Promoting the health of children and young people: setting the research agenda. London: Health Education Authority, 1998:51-61.

17 Kinnell H. Prostitutes, their clients and risks of HIV infection in Birmingham. London: Department of Public Health Medicine, 1989.
18 Boulton $M$. The methodological imagination. In: Boulton $\mathrm{M}$, ed. Challenge and innovation: methodological advances in social research on HIVIAIDS. London: Taylor and Francis, 1994

19 De Graaf R, Vanwesenbeecki I, van Zessen G, et al. Male prostitutes and safer sex: different settings, different risks. AIDS Care 1994;6:277-88.

20 Aggleton P. Evaluating health education about AIDS. In: Aggleton P, Hart G, Davies P, eds. AIDS: social representations, social practices. London: Falmer Press, 1989. 